\title{
REVESTIMENTO ELETROLÍTICO COM UMA LIGA AMORFA DE Ni-W-B, RESISTENTE À CORROSÃO E AO DESGASTE
}

\author{
R. A. C. de SANTANA ${ }^{1}$; S. PRASAD ${ }^{\prime *}$; F. S. M. de SANTANA ${ }^{1}$
}

\section{Resumo}

Estudou-se o processo de eletrodeposição de uma camada amorfa de liga Ni-W-B sobre um cátodo, utilizando um banho contendo sulfato de níquel $0,0185 \mathrm{M}$, tungstato de sódio $0,0155 \mathrm{M}$, fosfato de boro $0,0364 \mathrm{M}$, citrato de sódio $0,0161 \mathrm{M}, 1$-docecilsulfato de sódio $0,017 \mathrm{~g} / \mathrm{L}$ e hidróxido de amônio para $\mathrm{pH} 8,5$. Estudos detalhados sobre a influência da temperatura do banho, agitação mecânica e densidade de corrente catódica conduziram as condições ótimas para obtenção de depósitos de ligas satisfatórias. Observou-se que esta liga apresentou, elevada resistência à corrosão e ao desgaste quando comparadas com o cromo duro, além de se comprovar, através da difratometria de raios X, sua característica amorfa. Estas ligas podem ter grande utilidade em várias aplicações nas indústrias químicas, petrolíferas, petroquímicas, navais, de construções civis e automobilísticas em decorrência de algumas características especiais, como alta resistência à corrosão e desgaste e à capacidade de manter suas propriedades mecânicas em altas temperaturas.

Palavras-chave: Ligas Ni-W-B; eletrodeposição; corrosão; ligas amorfas; desgaste.

\section{Introdução}

A tarefa de escolher materiais para determinados equipamentos ou estruturas é bastante árdua, devido à grande variedade de materiais disponíveis, como por exemplo, os metais e suas ligas, os materiais poliméricos (plásticos e borrachas) e os materiais compósitos (cerâmica e madeira). Existem aproximadamente, oitenta metais puros, podendo-se obter, com boa parte destes, aproximadamente 40.000 ligas metálicas, [15] cada uma apresentando diferentes propriedades e, naturalmente, diferentes custos. $\mathrm{O}$ material ideal será aquele que apresentar as propriedades desejadas com o menor custo possível e, ainda, uma maior durabilidade. As propriedades físicas e mecânicas como dureza, resistência ao impacto, ductilidade, condutividade elétrica e térmica, soldabilidade etc., são intrínsecas aos materiais e, de certa forma, previsíveis. Na maioria dos metais e suas ligas, estes dados podem ser facilmente encontrados em literaturas ou determinados experimentalmente.

Entretanto, a durabilidade dos materiais, especificamente aqueles relacionados com a resistência à corrosão, depende tanto da natureza do meio em que os mesmo ficarão expostos, como das condições de exposição, sendo por isso de difícil previsão [11].

Os problemas de corrosão são freqüentes

Departamento de Engenharia Química - CCT - Universidade Federal de Campina Grande

CEP 58109-970 - Campina Grande - PB - Brasil 
e ocorrem nas mais variadas atividades, como por exemplo, nas indústrias químicas, petrolíferas, petroquímicas, navais, de construções civis, automobilísticas, nos meios de transportes: aéreo, ferroviário, metroviário, marítimo, rodoviário e nos meios de comunicação, como sistemas de telecomunicações, na odontologia (restaurações metálicas, aparelho de prótese), na medicina (ortopedia) e em obras de arte como monumentos e esculturas [7].

A conseqüência da corrosão pode ser apenas de ordem econômica como é o caso da corrosão de tubulações residenciais, veículos, eletrodomésticos etc., acarretando prejuízo econômico devido à manutenção ou substituição dos materiais corroídos. Em outros casos a corrosão poderá ocasionar graves acidentes com conseqüências sérias, tanto para a preservação da natureza, quanto do homem, como por exemplo, perfuração de tubulações de condução de gases combustíveis podendo causar incêndios ou contaminação, queda de pontes e viadutos. Podese verificar, portanto, que a corrosão é importante tanto do ponto de vista tecnológico como do ponto de vista social [5].

O processo da corrosão ocorre na superfície do metal e nas suas estruturas sob a influência do meio ambiente. As camadas protetoras, por outro lado, constituem uma importante prevenção contra a corrosão, particularmente contra a corrosão atmosférica. As principais camadas protetoras orgânicas são as tintas e os plásticos. As camadas protetoras inorgânicas mais relevantes são os metais, as películas de óxidos, os filmes de sais, os esmaltes etc.

As camadas metálicas protetoras são aplicadas por imersão a quente, cementação, revestimento mecânico, eletrodeposição, condensação de vapor do metal e pulverização do metal. Em conseqüência do desenvolvimento dos geradores de corrente contínua a prática da eletrodeposição tornou-se o processo mais utilizado para a proteção dos metais [13].

A eletrodeposição é o processo pelo qual um revestimento metálico é aplicado sobre uma superfície através de uma corrente elétrica, geralmente contínua. A deposição pode ser feita em superfície condutora (metais e ligas metálicas: aço carbono, latão) ou não-condutores (plásticos, couro, madeira) [14].

Com o propósito de se obter propriedades específicas, dois ou mais metais podem ser codepositados como uma liga metálica, resultando propriedades superiores àquelas oriundas da eletrodeposição de um simples metal. Em relação à eletrodeposição de um único metal, as ligas depositadas apresentam-se mais densas e mais duras, mais resistentes à corrosão em determinadas faixas de composição, melhores em propriedades magnéticas e mais adequadas para um posterior revestimento por eletrodeposição [3]. Os eletrodepósitos de níquel-cromo, por exemplo, são decorativos, melhorando a resistência à corrosão e proporcionam durabilidade e resistência à abrasão do metal subjacente.

A eletrodeposição geralmente é efetuada com soluções aquosas, utilizando sais simples ou complexos, ou pelo emprego de banhos de sais fundidos, se bem que estes sejam incomuns. $\mathrm{O}$ eletrólito da eletrodeposição, geralmente conhecido como banho eletrolítico, contém primariamente os íons que vão ser depositados associados a vários constituintes. Ditos constituintes compreendem o meio condutor necessário para o fluxo da corrente e, também funcionam como um agente tamponador para manter o $\mathrm{pH}$ da solução no nível requerido. Aditivos tais como agentes niveladores podem, geralmente, ser acrescentados aos banhos para prevenir pites de hidrogênio ou a acumulação de hidrogênio no cátodo. As soluções de sais complexos para eletrodeposição obviamente contêm vários complexantes, com a finalidade de manter o íon metálico como metal complexado na solução [4].

As ligas metálicas amorfas constituem uma nova classe de materiais em virtude de suas propriedades mecânicas, magnéticas, elétricas, catalíticas e de resistência à corrosão, devido a essas propriedades, decorrências diretas da estrutura homogênea, permite-se um comportamento diferente das ligas amorfas em relação às ligas cristalinas $[10,16,20]$. Historicamente, a primeira liga amorfa foi obtida por Kramer, em 1934, usando o método de deposição a vapor [12]. Brenner et al., em 1950, obtiveram as ligas por eletrodeposição [2]. Duwez, em 1967, desenvolveu um método de preparação de ligas por resfriamento rápido direto 
do material fundido, sendo, até o momento, o método mais utilizado na síntese de ligas amorfas [6].

A rigor, são desconhecidos todos os fatores que permitem obter uma liga amorfa eletroquimicamente. Em princípio, parece que a presença dos metalóides (como P, B etc.) que podem ser codepositados com alguns metais de transição, gera uma série muito grande de defeitos, os quais podem provocar distorções na rede, suficientes para conferir o caráter amorfo ao material [21].

O tungstênio possui um considerável interesse para ser eletrodepositado em forma de ligas, pois este metal apresenta propriedades bastante interessantes como: o mais alto ponto de fusão $\left(3.410^{\circ} \mathrm{C}\right)$, o que torna impossível depositálo termicamente sobre a superfície de qualquer outro metal, uma vez que este último muda de fase; o mais baixo coeficiente de dilatação linear térmica $\left(4,3 \times 10^{-6}{ }^{\circ} \mathrm{C}^{-1}\right)$; uma condutividade térmica muito alta $\left(0,487 \mathrm{cal} / \mathrm{cm}^{\circ} \mathrm{C}\right)$ e é um dos metais mais densos $\left(19,3 \mathrm{~g} / \mathrm{cm}^{3}\right)$. Tem propriedades mecânicas fora do comum, pois conserva sua dureza mesmo em altas temperaturas e tem a mais alta resistência à tração $\left(410 \mathrm{~kg} / \mathrm{mm}^{2}\right)$ e é muito resistente à corrosão. Além disso, não é atacado por nenhum ácido mineral simples na temperatura ambiente. Devido a esta insólita combinação de propriedades, o tungstênio tem inúmeras aplicações na indústria e na engenharia, não obstante o seu elevado preço e a sua relativa raridade. Por exemplo, suas boas propriedades mecânicas e elevadas temperaturas o tornam útil para ser usado em filamento de lâmpadas incandescentes, bocais de motores de foguetes e aços para ferramentas. O seu baixo coeficiente de expansão térmica permite a sua inserção no vidro "Pyrex". O metal é útil para contactos elétricos e para ligas resistentes à corrosão.

Apesar de numerosas afirmações, a eletrodeposição do tungstênio no estado puro, a partir de soluções aquosas ou orgânicas, não tem sido coroada de êxito [5,9]. Mas por outro lado, não há nenhuma dificuldade experimental na eletrodeposição do tungstênio com metais do grupo do ferro [1] com auxílio de algum agente complexante. Os banhos usualmente contêm o tungstênio como tungstato ao lado de sais dos metais do grupo do ferro e de algum agente complexante.
Os mais importantes dos primitivos trabalhos sobre a eletrodeposição de ligas de tungstênio foram aqueles devidos a vários pesquisadores russos, particularmente o trabalho de Goltz e Kharlamov, em 1936 [8]. Eles usavam soluções amoniacais para a deposição. Os depósitos obtidos eram, contudo, porosos e fracos. O próximo passo foi a introdução de ácidos hidroxiorgânicos nestes banhos amoniacais, a fim de torná-los mais estáveis e com elevada concentração metálica [22].

A bibliografia revela que, sob condições apropriadas da composição do banho e dos parâmetros de potencial e de corrente, uma liga amorfa pode ser depositada sobre um cátodo por eletrodeposição. Mas, em grande parte, a eletrodeposição de ligas amorfas está restrita a poucos sistemas de pequeno interesse prático direto ou não são conhecidos exemplos de eletrodeposição de ligas amorfas de alta dureza, resistentes ao desgaste e moderadamente dúcteis. Se for encontrada uma técnica que permita a produção de tais materiais, será possível, então, produzir, por exemplo, dutos resistentes à corrosão e ao desgaste mecânico. Muitas outras aplicações podem ser vislumbradas, incluindo, por exemplo, carcaças de bomba, orifícios de instrumentos, anéis de segmento etc.

Existe assim, a necessidade de um processo para preparar camadas de alta dureza, resistentes ao desgaste e à corrosão, de ligas amorfas moderadamente dúcteis, obtidas por eletrodeposição. Em face desta necessidade, foi encetado um trabalho com a finalidade de otimizar os parâmetros operacionais para eletrodeposição de ligas Ni-W-B resistentes à corrosão e ao desgaste. Resultados da eletrodeposição de ligas como Co-W-B e Co-Mo-B e estudos preliminares da liga de Fe-W-B, já foram publicados por este laboratório [17-19].

\section{Material e método}

Na preparação das soluções utilizadas neste experimento foram empregados reagentes com elevado grau analítico e água destilada em seguida deionizada.

A eletrodeposição foi conduzida de forma galvanostática. O ânodo consistia de uma malha 
cilíndrica oca de platina. Todas as ligas obtidas foram eletrodepositadas sobre o cátodo rotativo de cobre a velocidade constante, com o formato quadrado de $4,5 \mathrm{~cm}^{2}$ de área superficial. $O$ cátodo, ou substrato, era centralizado no interior do ânodo de platina, sem que houvesse contato entre ambos. Ao cátodo era aplicada uma densidade de corrente, utilizando-se para isto um potenciostato/ galvanostato Amel 555B. A temperatura do sistema era controlada por um termostato. A agitação mecânica era conferida na forma de rotação catódica, mediante o uso de um eletrodo rotativo EG\&G PARC 616.

O banho eletrolítico utilizado para eletrodeposição da liga amorfa de Ni-W-B está apresentado na Tabela 1 [17]. O fosfato de boro foi adicionado ao banho para fornecer uma fonte de boro para a liga, tornando-a amorfa. $\mathrm{O}$ citrato de sódio foi adicionado como agente complexante para garantir a estabilidade do banho. O 1dodecilsulfato-Na foi adicionado como agente surfactante para reduzir os pites de hidrogênio. $\mathrm{O}$ $\mathrm{pH}$ do banho foi ajustado com hidróxido de amônio.

\begin{tabular}{|c|c|}
\hline Componente & Concentração \\
\hline $\mathrm{Va}_{2} \mathrm{WO}_{4} \cdot 2 \mathrm{H}_{2} \mathrm{O}$ & $0,0155 \mathrm{M}$ \\
\hline $\mathrm{NiSO}_{4} 6 \mathrm{H}_{2} \mathrm{O}$ & $0,0185 \mathrm{M}$ \\
\hline $\mathrm{BPO}_{4}$ & $0,0364 \mathrm{M}$ \\
\hline $\mathrm{Na}_{2} \mathrm{C}_{4} \mathrm{H}_{5} \mathrm{O}-2 \mathrm{H}_{2} \mathrm{O}$ & $0,0161 \mathrm{M}$ \\
\hline L-todecrilsulfato de sódio & $0.017 \mathrm{~g} / \mathrm{L}$ \\
\hline $\mathrm{NH}_{3}($ aq) para ajustamento de $\mathrm{pH}$ para 8,5 & \\
\hline
\end{tabular}

Tabela 1: Composição do banho eletrolítico de ligas NiW-B [17].

Foram estudadas as seguintes variáveis operacionais: densidade de corrente catódica, temperatura e agitação mecânica do banho eletroquímico. Para realização deste estudo foram mantidas duas varáveis operacionais constantes e variava-se a terceira.

Para o estudo da corrosão foram executados dois ensaios: o de jato de sal (jato de uma solução a 3,5\% de $\mathrm{NaCl}$ com a duração de uma semana) e o de atmosfera de $\mathrm{H} 2 \mathrm{~S}$ (solução $5 \%$ de $\mathrm{NaCl}$, com pH ajustado para 3,2, com ácido acético e saturado com $\mathrm{H} 2 \mathrm{~S}$ à temperatura ambiente).

$\mathrm{O}$ ensaio ao desgaste de coberturas amorfas foi realizado com o emprego de um Standard Taber Abraser provido de uma roda CS e uma carga de 500g. As placas de ensaio do Steel Taber foram eletrodepositados com cromo duro e uma liga de Ni-W-B, obtida pelo método dos autores. Estas provas foram rodadas 10.000 vezes.

A caracterização da estrutura amorfa foi realizada utilizando-se a difratometria de raios $\mathrm{X}$ de uma liga de Ni-W-B depositada sobre um substrato de cobre, usando a radiação K-alfa do cobalto.

\section{Resultados e discussão}

O controle das variáveis operacionais é muito mais importante na deposição de ligas do que na deposição de um único metal. No caso da deposição de ligas, pequenas mudanças nas condições de revestimento podem alterar consideravelmente a composição e as propriedades do depósito. Geralmente, espera-se que um aumento da densidade de corrente favoreça a deposição do metal menos nobre, e um aumento na temperatura ou na agitação do banho cause um aumento na deposição do metal mais nobre. Mas os efeitos das variáveis operacionais no caso de codeposição induzida, tal como na eletrodeposição de ligas NiW-B, são complicados e não podem ser previstos

\section{Efeito da agitação mecânica}

A agitação mecânica, aqui implementada sob forma de rotação catódica, pode afetar diretamente a composição da liga pela redução da camada de difusão no cátodo e por manter a concentração do metal ao redor do cátodo relativamente igual à concentração no corpo da solução. A concentração dos complexantes livres na camada de difusão do cátodo é também reduzida pela agitação, que pode promover um efeito poderoso sobre o potencial de um ou ambos os metais. Também, há a possibilidade da tendência da composição da liga resultar de uma redução na concentração de agente complexante livre, podendo ser oposta no sentido de que resulta de um aumento na concentração de íon de metal na camada de difusão de cátodo. Tal possibilidade pode acontecer em um sistema de deposição da liga onde apenas o metal menos nobre forma complexo com o agente complexante. Isto significa que, em banhos contendo íons complexos, o efeito da agitação não é tão previsível quanto nos casos de banhos constituídos por íons simples.

O efeito da agitação mecânica foi estudado

Ecl. Quím., São Paulo, 28(1): 69-76, 2003 
fixando-se a temperatura em $70^{\circ} \mathrm{C}$ e a densidade de corrente em $30 \mathrm{~mA} / \mathrm{cm}^{2}$ (Figura 1). Pode-se observar que, com a agitação mecânica igual a $20 \mathrm{rpm}$ foram obtidos os melhores resultados de eficiência catódica. A mudança da eficiência catódica com a agitação mecânica não pode ser explicada somente pela simples transferência de massa, devendo ser incluído algumas seqüências de reações complexas envolvendo uma série de etapas de transferência eletrônica [4] e modificações na superfície do eletrodo; o que pode explicar o baixo valor de eficiência catódica a $40 \mathrm{rpm}$. As ligas obtidas a 5 rpm produziram um depósito cinza-escuro, provavelmente devido à redução parcial do óxido de tungstênio. Acima de $20 \mathrm{rpm}$, as ligas eletrodepositadas apresentaram-se não aderentes, com formação de escamas. As ligas obtidas a 20 rpm, além de possuírem alta eficiência catódica, apresentaram boa aderência.

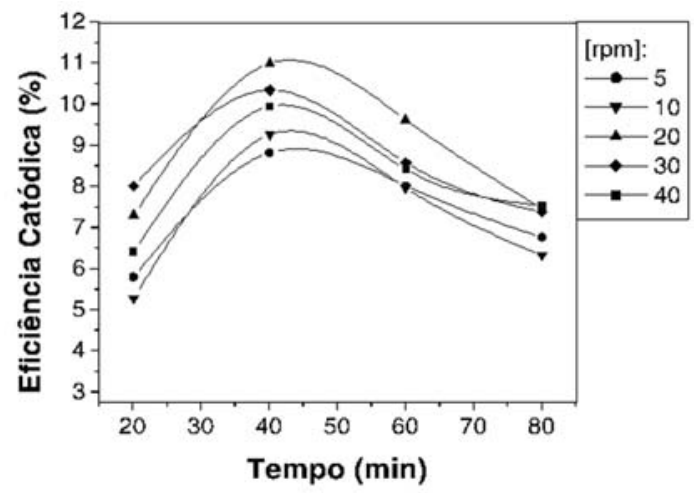

Figura 1. Efeito da agitação mecânica na eficiência de corrente catódica, utilizando o banho da Tabela 1 , densidade de corrente de $30 \mathrm{~mA} / \mathrm{cm}^{2}$, temperatura de $70^{\circ} \mathrm{C}$.

\section{Efeito da temperatura}

Um aumento no valor da temperatura usualmente faz decrescer a polarização, aumenta a concentração de metal na camada de difusão e pode afetar a eficiência de corrente catódica da deposição do metal, particularmente aqueles depositados a partir de íons complexos.

Uma série de eletrodeposições foi realizada para diferentes valores de temperatura, desde 25 a $90{ }^{\circ} \mathrm{C}$. A rotação catódica utilizada em todos os ensaios era de $20 \mathrm{rpm}$, valor já otimizado, enquanto que a densidade de corrente era fixada em $30 \mathrm{~mA} / \mathrm{cm}^{2}$. A variação da eficiência catódica com a temperatura é mostrada na Figura 2, nela pode ser visto que a liga depositada com melhor eficiência foi obtida na temperatura de $50^{\circ} \mathrm{C}$. Nesta condição, foram obtidas ligas com as melhores propriedades físicas.

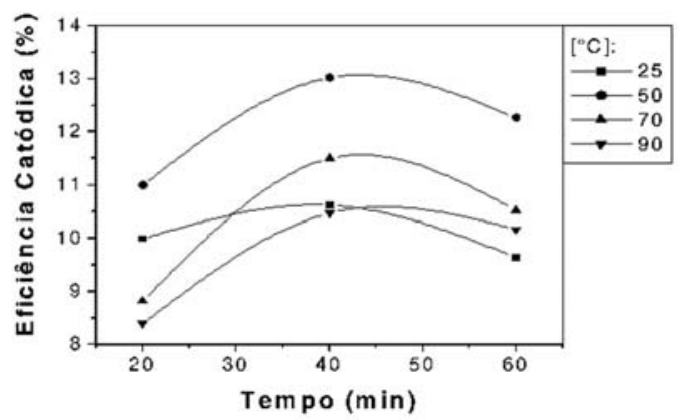

Figura 2. Efeito da temperatura na eficiência de corrente catódica, utilizando o banho da Tabela 1, densidade de corrente de $30 \mathrm{~mA} / \mathrm{cm}^{2}$, agitação mecânica de $20 \mathrm{rpm}$.

\section{Efeito da densidade de corrente}

A densidade de corrente é a mais importante das variáveis operacionais. $\mathrm{O}$ processo de eletrodeposição de ligas poderia ser explicado pela teoria da difusão. Infelizmente, nenhuma explicação simples e semelhante pode explicar todo o mecanismo de sistemas de codeposição induzida com relação à densidade de corrente.

Experimentos iniciais de eletrodeposição de ligas Ni-W-B foram realizados com densidade de corrente na faixa de 10-90 mA/ $\mathrm{cm}^{2}$. Observou-se que uma camada amorfa de boa qualidade podia ser obtida com uma faixa relativamente estreita de densidade de corrente. A Figura 3 mostra o comportamento da eficiência catódica com a densidade de corrente catódica. $\mathrm{O}$ valor ótimo de densidade de corrente foi 50 $\mathrm{mA} / \mathrm{cm}^{2}$. Abaixo deste valor, os depósitos tendem a formar estruturas cristalinas. Valores mais altos conduzem a ligas de baixa qualidade com formação de depósitos escuros. 


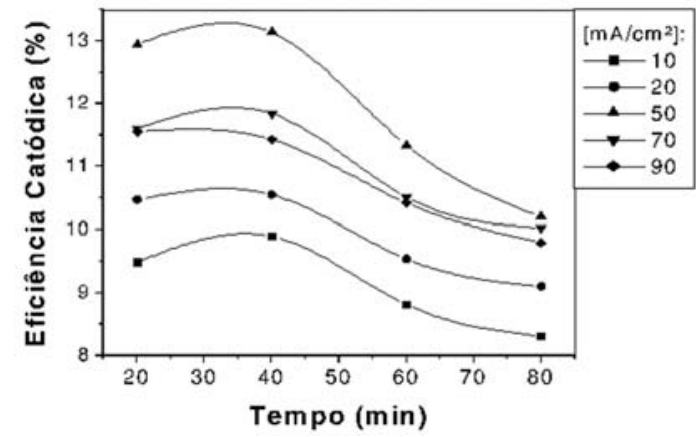

Figura 3. Efeito da densidade de corrente na eficiência de corrente catódica, utilizando o banho da Tabela 1, agitação mecânica de $20 \mathrm{rpm}$ e temperatura de $50^{\circ} \mathrm{C}$.

\section{Resistência à corrosão}

Foi constatado que a resistência à corrosão das ligas eletrodepositadas é muito superior àquela referente ao cromo duro. Foram realizados os seguintes ensaios:

1. Ensaios de corrosão pelo jato de sal (jato de uma solução a 3,5\% de $\mathrm{NaCl}$ com a duração de uma semana) - não houve qualquer evidência de corrosão da liga de Ni-W-B, entretanto o cromo duro foi descorado e mostrou pontos de corrosão.

2. Ensaios de Corrosão em atmosfera de $\mathrm{H}_{2} \mathrm{~S}$ - não foi observado qualquer sinal de corrosão sobre a placa com a liga Ni-W$\mathrm{B}$, durante o período de sete dias. $\mathrm{O}$ cromo duro, por outro lado, começou a apresentar sinais de corrosão a partir do primeiro dia.

As experiências voltamétricas mostraram que em meio neutro e básico, a liga ficou protegida da corrosão devido à formação de uma camada estável de óxido de níquel trivalente na superfície [9]. Em meio ácido, o tungstênio protege a liga em virtude da formação de $\mathrm{WO}_{3}$ ou ácido metatungstico, apresentando comportamento semelhante ao da liga de Ni-Mo-B.

\section{Resistência ao desgaste}

Os resultados obtidos são apresentados na Figura 4. O cromo duro mostrou uma taxa de desgaste linear durante todo o ensaio, ao passo que a liga de Ni-W-B começou com um desgaste levemente mais alto, mas rapidamente teve a sua taxa diminuída. Provavelmente, este fenômeno é devido à natureza muito nodular da cobertura amorfa superficial da liga, que sofre o impacto da elevada carga no início do ensaio.

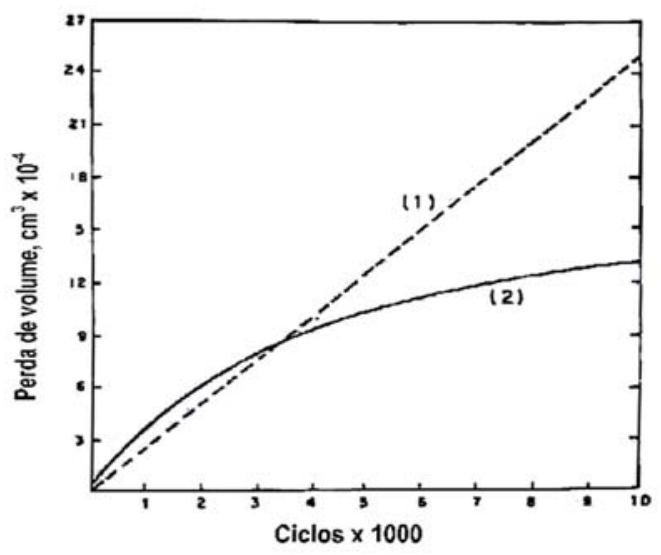

Figura 4. Taber Abraser Test. Roda CS-17, carga de 500g. (1) cromo duro; (2) liga de Ni-W-B.

\section{Características amorfas da liga}

A Figura 5 ilustra um difratograma de raios $\mathrm{X}$ da liga amorfa de Ni-W-B com $0,05 \mathrm{~cm}$ de espessura. O pico simples expandido é característico da estrutura totalmente amorfa, com isso podemos afirmar que a liga possui características amorfas.

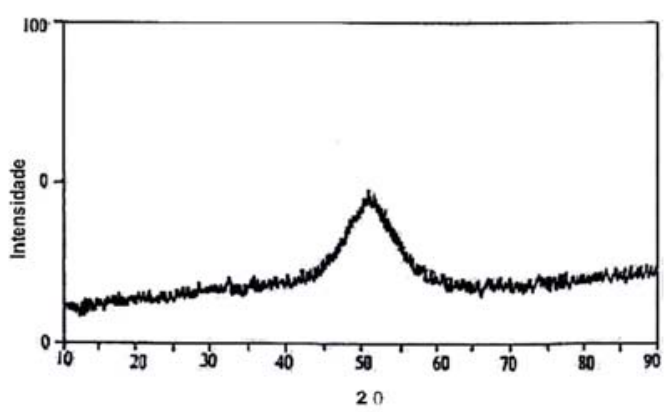

Figura 5. Difração de raios $X$ de uma liga amorfa de Ni-W-B, com 0,005 $\mathrm{cm}$ de espessura, depositada sobre um substrato de cobre, com o banho eletrolítico e os parâmetros operacionais otimizados.

Ecl. Quím., São Paulo, 28(1): 69-76, 2003 


\section{Caracterização da composição da liga}

Para o estudo da composição dos componentes da liga de Ni-W-B foi utilizada a técnica de absorção atômica que apresentou a seguinte composição média: $68,5 \%$ de níquel, 30,0\% de tungstênio e $1,5 \%$ de boro.

\section{Conclusão}

Os resultados deste estudo sugerem que os valores ótimos de operação do sistema de eletrodeposição são: temperatura do banho de 50 ${ }^{\circ} \mathrm{C}$, agitação mecânica de $20 \mathrm{rpm}$ e densidade de corrente catódica de $50 \mathrm{~mA} / \mathrm{cm}^{2}$. Foi também constatado, que a resistência à corrosão da liga eletrodepositada é muito superior àquela observada para o cromo duro. A liga apresentou elevada resistência ao desgaste quando isso comparada com o cromo duro. Foi confirmado pelo difartograma de raios $\mathrm{X}$ que a liga estudada possui característica amorfa.

\section{Agradecimentos}

Os autores agradecem ao CNPq e ao $\mathrm{PRH}(25) / \mathrm{ANP} / \mathrm{MME} / \mathrm{MCT}$ pelo apoio financeiro e à Professora Janet G. Osteryoung, do Departamento de Química da North Carolina State University, Raleigh, NC, U.S.A, pela contribuição na realização de alguns ensaios e pelas valiosas sugestões.

SANTANA, R. A. C. de; PRASAD, S.; SANTANA, F. S. M. de. Electrolytic coating with corrosion and wear resistant Ni-W-B amorphous alloy.

\section{Abstract}

The process of electrodeposition of amorphous layer of Ni-W-B alloy on a cathode, using a bath containing $0.0185 \mathrm{M}$ nickel sulfate, $0.0155 \mathrm{M}$ sodium tungstate, $0.0364 \mathrm{M}$ sodium citrate, 0.017 $\mathrm{g} / \mathrm{L}$ 1-dodecylsulfate-Na and ammonia for $\mathrm{pH}$ adjustment to 8.5 , has been studied. Detailed studies on bath temperature, bath agitation and cathode current density led to the optimum conditions for obtaining satisfactory alloy deposit. The alloy presented higher corrosion and wear resistance in comparison to the hard chromium, besides its amorphous characteristic verified by X-ray diffraction.
These alloys should have great importance in various applications in chemical, petroleum, petrochemical, naval, automobile and civil construction industries due to their special characteristics such as high wear and corrosion resistance and the capacity to maintain their mechanical properties at high temperatures.

Keywords: Ni-W-B alloys; electrodeposition; corrosion; amorphous alloys; wear.

\section{Referências bibliográficas}

[1] BRENNER A. Electrodeposition of alloys. New York: Academic Press, 1963.

[2] BRENEER, A.; COUCH, D. E.; WILliAMS, E. K. Electrodeposition of alloy of phosphorus with nickel or cobalt. J. Res. Natl. Bur. Standards, v. 44, p. 109-122, 1950 .

[3] BURNS, R. M.; BRANDEY, W. W. Protective coatings for metals. New York: Reinhold Publishing Corporation, 1995 .

[4] CHASSAING, E.; VU QUANG K.; WIART R. Mechanism of nickel-molybdenum alloy electrodeposition in citrate electrolytes. J. Appl. Electrochem., v. 18, p. 839$843,1989$.

[5] DAVIS, G. L.; GENTRY, C. H. R. The electrodeposition of tungsten. Metallurgia, v. 53, p. 3-17, 1956.

[6] DUWEZ, P. Rapidly chilled amorphous alloy films. U.S. Patent 3,297,436, jan. 1967. Trans. Am. Soc. Metals, v. 60, p. 607-616, 1967.

[7] GENTIL, V. Corrosão. Rio de Janeiro: LTC, 1996.

[8] GOL'TZ, L. N.; KHARMALOV, V. N. Electrolytic deposition of alloys of tungsten, nickel and copper from water solution. Zhur. Priklad Khim, v. 9, p. 640-652, 1936.

[9] GUIMARÃES, T. L. M. Estudos sobre banhos para eletrodeposição de ligas de Ni-Mo-B. 80 f. 1996. Dissertação (Mestrado em Engenharia Química) Universidade Federal da Paraíba, Paraíba, 1996.

[10] HOLT, M. L. Less-common metals and alloys. Metal Finish, p. 48-55, 1956.

[11] KASIMOTO, Z. P.; ALMEIDA, N. L.; SIQUEIRA, F. J. S. Corrosão atmosférica de metais no Estado de São Paulo. São Paulo: IPT, 1991. 86 p.

[12] KRAMER, J. Noconducting modification of metals. J. Annln. Phy., v. 19, p. 37-64, 1934. 
[13] LANDAU, U. Plating: new prospects for an old art. In: LANDAU, U.; YEAGER, E.; KORTAN, D. (Ed.). Electrochemistry in industry: new directions New York: Plenum Press, 1980. p. 215-245.

[14] METAL handbook. 9th ed. Metals Park: ASM, 1987. v.5.

[15] NACE. Basic corrosion course. Houston, 1975. 15 p.

[16] NAGEL, S, R. Advanced chemical physics. New York: Wiley, 1982. p. 227-275.

[17] PRASAD, S. Eletrodeposição de camadas de liga níqueltungstênio e determinação de níquel por voltametria de onda quadrada. Tratamento de Superficie, v. 58, p. 23-28, 1993.

[18] PRASAD, S. Electrodeposition of tungsten alloys with cobalt, nickel and iron. Proc. Interfinish. LatinoAmeric., p.107, 1997.

[19] PRASAD, S.; MARINHO, F. A.; SILVA, L. B. A comparative study on electrodeposition of Fe-W-B and Fe-Mo-B alloys. J. Indian Chem. Soc., v. 77, p. 311-313, 2000 .

[20] SEARSON, P. C.; NAGASKAR, P. V.; LATANISION, R. M. In: WHITE, R. E.; BOCKRIS, J. O. M.; CONWAY, R. B. (Ed.). Modern aspects of electrochemistry. New York: Plenum Press, 1990. p.121-161.

[21] STAFFORD, G. R. The eletrodeposition of an aluminium-manganes metallic glass from molten salts. In: DIEGLE, R. B.; HASHIMOTO, K. (Ed.). Proceeding of the symposium on corrosion, eletrochemistry and catalysis of metallic glasses. Princeton: The Electrochemical Society, 1988

[22] VAALER, L. E.; HOLT, M. L. Codeposition of tungsten and nickel from an aqueous ammoniacal citrate bath. Trans. Electrochem. Soc., v. 90, p. 43-53, 1946.

[23] WOLYNEC, S. Corrosão de metais: definição e principais tipos. In: SIMPÓSIO DE MATERIAIS DE CONSTRUÇÃO, DURABILIDADE DOS MATERIAIS E COMPONENTES DE CONSTRUÇÃO CIVIL, 2., 1988, São Paulo. Anais... São Paulo: EP/USP,1988. p. 15-31.

Recebido em:03/02/03

Aceito em :23/04/03 